\title{
Online Teacher Work to Support Self-Regulation of Learning in Students with Disabilities at a Fully Online State Virtual School
}

\author{
Mary F. Rice and Richard Allen Carter, Jr. \\ University of Kansas
}

\begin{abstract}
Students with disabilities represent a growing number of learners receiving education in K-12 fully online learning programs. They are, unfortunately, also a large segment of the online learning population who are not experiencing success in these environments. In response, scholars have recommended increasing instruction in self-regulation skills for these students, but whether teachers are able to promote self-regulation as part of their instruction and how they will do so remains unknown. The purpose of this qualitative study was to examine how practicing teachers provided self-regulation strategies to students with disabilities in a fully online learning environment. In this context, the teachers intended to offer self-regulation strategies to students, but they were largely unable to do so. This work has the potential to influence professional development programs for online teachers in the hopes that students with disabilities will be able to learn self-regulation strategies and ultimately be more successful.
\end{abstract}

Keywords: self-regulation, practicing online teachers, students with disabilities, teacher thinking about strategies, K12 virtual schools, online learning policy

\section{Introduction}

The International Association for K-12 Online Learning (iNACOL) defines online learning as an educational system in which instruction and content are delivered primarily over the Internet (Watson \& Kalmon, 2005). Presently, all 50 states offer online learning to K-12 students in some form (Gemin, Pape, Vashaw, \& Watson, 2015). Accordingly, there has been an increase in the number of students being educated in online learning environments over the past 15 years (Watson, Pape, Murin, Gemin, \& Vashaw, 2014). Though access to online learning environments is increasing, desired educational outcomes have not risen proportionately. 
Students being educated in online learning environments are less likely to complete their coursework than corresponding courses in traditional brick-and-mortar learning environments (de la Varre, Irvin, Jordan, Hannum, \& Farmer, 2014). Outcomes for students with disabilities in online learning environments are still more troubling. In a recent study in a large Midwestern virtual school program, Deshler, Rice, and Greer (2014) found that having an identified disability was the only demographic characteristic of nine characteristics tested that predicted low course grades.

Furthermore, there is little research investigating how to best serve students with disabilities and other diverse populations in online learning settings (Fernandez, Ferdig, Thompson, Schottke, \& Black, 2016). Though the field has just begun to investigate how to best assist students with disabilities in these settings, they are still required to meet high academic standards typical to their peers (Deshler, Smith, Greer, \& Rice, 2014). A few states have addressed these concerns through policy or guidance documents (Basham, Stahl, Ortiz, Rice, \& Smith, 2015), but in general, educators and administrators are left on their own to search for strategies to best serve students with disabilities in online learning environments.

Since the online learning environment places increased demands on the learner, including goal setting, problem-solving, and determination, some researchers have suggested improving self-regulation learning skills in students who struggle in order to decrease attrition (Barbour \& Mulcahy, 2004; Cavanaugh, 2007; Friedhoff, 2015). Self-regulated learning "refers to the self-directive processes and self-beliefs that enable learners to transform their mental abilities, such as verbal aptitude, into an academic performance skill” (Zimmerman, 2008). Despite its potential, self-regulated learning remains under-researched, especially in the area of online learning environments for students with disabilities. Further, although self-regulated learning may benefit students, teachers are the ones expected to cultivate these skills in students. The level of preparation they have received also remains unknown. The purpose of this study was to uncover strategies teachers of students with disabilities used to promote self-regulation of learning among students during online coursework.

\section{Conceptualizing Self-Regulation in Online Learning Environments}

Several models of self-regulated learning have emerged in the research literature over the last 30 years. Educational psychologist Paul Pintrich is credited with developing and promoting the first conceptualization of self-regulated learning as one aspect of self-regulation (Pintrich \& DeGroot, 1990). Pintrich's model of self-regulated learning identified metacognition (thinking about thinking), strategic action (planning and monitoring personal progress), and motivation to learn (desire to learn generally or specific subject matter) as critical dimensions (Butler \& Winne, 1995; Boekerts \& Corno, 2005).

Subsequent models of self-regulated learning have drawn on Pintrich's original work (Pintrich \& DeGroot, 1990). Pintrich himself (2004) noted that all models of self-regulated learning are based on four assumptions. Table 1 offers additional information about each of them. First, self-regulated learning models assert that learning is an active process, and learners will construct meaning from information found in the environment as well as information from thinking. In addition, Pintrich distinguished environmental information as external and 
information from within as internal. Learners use both sources of information to self-construct important aspects of learning, including goals and learning strategies.

Table 1

Assumptions, Meanings, and Outcomes for Self-Regulation of Learning

\begin{tabular}{|c|c|c|}
\hline Assumption & Definition & Outcome \\
\hline $\begin{array}{l}\text { Active, constructive } \\
\text { assumption }\end{array}$ & $\begin{array}{l}\text { Learning is an active process with the } \\
\text { student constructing aspects of their } \\
\text { learning based on internal and } \\
\text { external environmental factors. }\end{array}$ & $\begin{array}{l}\text { Students will construct: } \\
\cdot \quad \text { Meanings } \\
\cdot \quad \text { Goals } \\
\cdot \quad \text { Strategies }\end{array}$ \\
\hline $\begin{array}{l}\text { Potential for control } \\
\text { assumption }\end{array}$ & $\begin{array}{l}\text { Students have some control over their } \\
\text { ability to monitor aspects of the } \\
\text { learning process. }\end{array}$ & $\begin{array}{ll}\text { Students will monitor: } \\
\cdot \quad \text { Cognition } \\
\cdot \text { Motivation } \\
\cdot \quad \text { Behavior } \\
\cdot \quad \text { Environment }\end{array}$ \\
\hline Goal assumption & $\begin{array}{l}\text { Students work towards defined goals, } \\
\text { and progress towards these goals } \\
\text { determines whether students should } \\
\text { alter aspects of the learning process to } \\
\text { meet their goals. }\end{array}$ & $\begin{array}{l}\text { Students will adapt: } \\
\cdot \text { Cognition } \\
\cdot \text { Motivation } \\
\cdot \text { Behavior }\end{array}$ \\
\hline $\begin{array}{l}\text { Mediators between } \\
\text { characteristics and } \\
\text { performance assumption }\end{array}$ & $\begin{array}{l}\text { Self-regulation of learning processes } \\
\text { serves as a mediator between } \\
\text { learners, context, and achievement. }\end{array}$ & $\begin{array}{l}\text { Self-regulation of learning: } \\
\cdot \text { Operates differently for } \\
\text { learners in various environments; } \\
\text { even so, it } \\
\text { predicts achievement }\end{array}$ \\
\hline
\end{tabular}

Second, self-regulated learning models assume that learners have some level of control over cognition, strategic behavior, motivation, as well as aspects of the environment. Learners control these components through self-monitoring processes. Admittedly, this assumption is undertheorized since it does not take into account the wide variance of learners and characteristics that impact the learner's ability to control these crucial aspects of self-regulated learning. Even so, the assumption draws attention to the fact that learners can act with some agency when they are faced with tasks in educational settings.

The third assumption contends that there is a goal in place that learners can use to gauge whether they are learning and are ready to move to new content. In theory, such self-monitoring allows the learner to progress through the learning process by setting attainable goals. Individuals with well-developed self-regulated learning skills will continually assess their progress toward goals and make adjustments that allow them to reach them. Inevitably, selfmonitoring processes lead to micro-episodes of self-regulated learning within larger, overarching plans for achieving entire learning tasks and meeting goals for learning in a course.

Finally, self-regulated learning models assume that neither environment nor personal characteristics are the biggest determinants of learning. Individual achievement is mostly controlled by the learner through their use of self-regulated learning skills. In this assumption, 
any learner who enacts self-regulated learning strategies will progress, regardless of other factors. All four of these assumptions come together to promote student autonomy in learning.

Historically, self-regulation skills have been taught in traditional face-to-face settings, with teachers mediating self-regulation skills for students through direct instruction (Sawyer, Graham, \& Harris, 1992). For example, a teacher in a traditional school setting might notice students struggling with a math problem. The teacher could prompt them to use a specific strategy to answer the problem. That strategy could be taught at that exact moment, or it could be referenced from strategies that students have learned previously in that class or in another other setting.

Although self-regulated learning is regarded as the path to learner autonomy, students do not enter learning environments knowing proper strategies or how to enact them. This is particularly true for young learners since most of their self-regulation skills mimic those of parents or other adult caregivers (Bernier, Carlson, \& Whipple, 2010). School settings, then, are often the places where children first make connections between other self-regulatory factors, such as self-efficacy and self-regulation of learning (Schunk \& Zimmerman, 2007). As a result, helping students understand how to orchestrate autonomous self-regulated learning falls primarily on teachers. Moreover, students with disabilities in traditional settings are in particular need of teachers who can notice and teach or remind them of a strategy (Fritschmann, Deshler, \& Schumaker, 2007). For instance, Graham and Harris (1993) found that the quality of students with disabilities' writing improved when teachers showed students how to use planning and revision strategies during composition. In a similar study, Harris, Graham, and Mason (2006) found that when teachers introduced students to self-regulation of learning strategies, the students with disabilities spent more time planning before starting writing activities.

In using the word "strategy," we do so in keeping with the relatively global reference to various cognitive processes and behaviors that students can employ in order to accomplish selfset goals or goals implied by an academic task (Weinstein \& Mayer, 1986). In environments where students are engaging with technologies to learn, the need for strategies is heightened for three reasons. First, technology is simultaneously stimulating and distracting (Wehmeyer, Smith, Palmer, \& Davies, 2004). Second, students with disabilities may be used to having teachers or paraprofessionals prompt them to use strategies and coach them through difficulties. Thus, they are used to this type of direct support. Third, if students have not previously been supported by educators, they are likely to have few strategies for self-regulating their learning when they start learning wholly or partially online.

Taken together, these studies suggest that self-regulation of learning can be taught successfully to students with disabilities; therefore, there is a need to understand how teachers conceptualize self-regulation of learning in online environments and how they understand their roles in supporting students in learning these skills. Finally, since students with disabilities are understood to be in much more need of teacher support for self-regulated learning, alongside the newness of learning online, it is especially important to understand teacher thinking about selfregulation as part of their work with these students. 


\section{Research Methods and Strategies}

The research design employed in this work was a case study (Merriam, 1998; Yin, 2011). In a case study, multiple strategies are employed by a researcher or a team of researchers to gather as much information as possible about the phenomenon under study. In this case, the participants were assigned to the same special education mentors. Furthermore, all the teachers had students with disabilities in their classes who were not seniors, which enabled researchers to access teachers' efforts with students at other places in their high school careers. This case study was planned with the criteria for credibility in mind: (1) prolonged engagement, (2) persistent observation, (3) peer debriefing, (4) member checking, (5) audit trails, and (6) descriptive details (Lincoln \& Guba, 1985). These elements are evident in the descriptions that follow.

\section{Identifying and Inviting Participating Teachers}

Four content teachers with special education certification in a large state virtual school participated in this case study. Student loads for these teachers were around 150 students at the time of the study, with as many as $50 \%$ having a disability or some other type of special need. These teachers shared many of these students, and they met to discuss their students with disabilities and receive support from special education administrators once per week. They were invited into the study because they worked in a large virtual school program with more than 20,000 enrollments per year. This criterion for a large school was important for establishing the context as the kind that many students would experience, rather than only a few. In addition, we wanted to find teachers serving students at a variety of grade levels and who were taking courses for a variety of reasons. At this school, the students were in grades 9-12, and they were earning credit for graduation: both initial credit and, in some cases, as part of credit recovery. Although the school had a full-time option, these teachers were working in a part-time program where students did not have a full load of virtual classes. In order to identify the specific teachers, the virtual school was contacted, and an administrator facilitated the invitation to this group, all of whom were both subject matter and special-education certified. All four invited teachers agreed to participate. Table 2 offers a summary of information about the participants. Names given in this article are pseudonyms.

Table 2

Participating Teacher Information

\begin{tabular}{lllll}
\hline Teacher & Subject & $\begin{array}{l}\text { Years of } \\
\text { experience } \\
\text { teaching online }\end{array}$ & $\begin{array}{l}\text { Total years of } \\
\text { experience } \\
\text { teaching }\end{array}$ & $\begin{array}{l}\text { Number of } \\
\text { interviews }\end{array}$ \\
Ms. Smith & $\begin{array}{l}\text { English language } \\
\text { arts }\end{array}$ & 8 & 21 & 6 \\
Ms. Cassidy & $\begin{array}{l}\text { English language } \\
\text { arts }\end{array}$ & 5 & 8 & 5 \\
Ms. Bongiovi & Math & 6 & 16 & 6 \\
Ms. Cardio & Physical education & 5 & 15 & 6 \\
\hline
\end{tabular}




\section{Data Sources}

The data sources for this study included a record of interactions with parents, students, and teachers around accommodations for students with disabilities, including the implementation of their Individualized Educational Plans (IEPs) and individual interviews with the participating teachers. Multiple data sources were used in order to increase the credibility of the findings (Marshall \& Rossman, 2014). The participating school provided the record of participating teachers' interactions with parents, students, and colleagues. Data about the types of disabilities that students had who were attending the school or information about students that served as the impetus for the contact with teachers or administrators were present in contact records. Data about individual student performance or information from IEPs that could be linked directly to individual students were not collected. Table 3 outlines the major data sources.

Table 3

Information about Major Data Sources

\begin{tabular}{|c|c|}
\hline Data source & Description \\
\hline Contact log & $\begin{array}{l}\text { When teachers made contact with students and/or other staff, they were required } \\
\text { to enter the date, the purpose of the contact, and the outcome of the contact. }\end{array}$ \\
\hline Interviews & $\begin{array}{l}\text { Teachers were asked about their self-regulation of learning contact with } \\
\text { students. These questions included: How many students have contacted you } \\
\text { today? What did they need help with? How did you respond? What strategies } \\
\text { did you offer them? How did you decide what strategy would be helpful? How } \\
\text { is what you recommended different for a student with a disability versus a } \\
\text { student without? }\end{array}$ \\
\hline
\end{tabular}

Student records $\quad$ Records of course completion, final testing, and IEP accommodations for students with disabilities

Another data source included individual phone interviews with the four teachers and their special education mentors. These interviews were conducted once per week for six weeks during the study period. These interviews lasted between 30 minutes and one hour. The length of these interviews varied depending on the teachers' other assigned professional duties on a given day, the number of calls or other initiations of communication received from students in a given day, and their personal circumstances. During the course of the study, only three interviews had to be entirely canceled and rescheduled due to the teachers' schedules. The additional data sources enabled verification of the teachers' stories through triangulation (Mathison, 1988). Thus, interviews with teachers were interpreted against interviews with the special education administrators mentoring them, along with electronic logs required by the school that both teachers and administrators updated regularly. 


\section{Data Analysis}

Each interview was recorded and transcribed. Researchers met approximately six times over the course of three months to analyze the data and record consensus as it emerged. Interview data was coded using open and axial coding germane to grounded theory procedures commonly adopted into qualitative research (Charmaz, 2006). Next, data underwent an additional round of analysis, where tension emerged as the dominant structure for understanding the data (Clandinin, Murphy, Huber, \& Orr, 2009). These researchers use the word "tension" to describe seemingly contradictory positions on an educational landscape. In this framework, contradictions are often healthy because school settings are filled with various institutional demands that challenge or extend the intentions of individuals who have some overlapping and shared responsibilities for students. For example, schools often have accountability demands that teachers deem problematic for individual students because they have more information (or they suppose that they do) about specific children. As a result, teachers experience tension as they try to impose the demands while also being sensitive to individual cases. In a similar manner, a teacher may experience tension in negotiating with parents who desire a particular opportunity for their own child while the teacher feels an obligation to ensure fairness to the entire class.

When tensions began to emerge as the dominant structure for interpreting the data, it became necessary to revisit the data, record the instances of tension carefully to provide evidence for the developing audit trail, and then engage in negative case analysis techniques (Marshall \& Rossman, 2014). Such techniques seek to identify contradictory evidence of the uncovered tension. In addition, negative case analysis helps researchers review and develop deeper understandings of the data. In summary, initial codes developed into the structure of a tension, where research conclusions were modified, and the evidence in the data set could be reconciled with the teachers who were provided initial transcripts for review, copies of the findings, and explanations. When the teachers received the findings, they made clarifications regarding the timeline of the study, which were reflected in this manuscript, but they made no additions to the findings. Their additional commentary suggested that they felt relief that their colleagues had similar experiences. The analysis procedures of looking for tensions and doing member checks were designed to provide some assurance that the themes represented all four teachers as much as possible. Our attempts to establish resonance throughout the group signify that the findings section represents the collective understanding of the teachers and not individual understandings. Therefore, we have framed the discourse of the findings as "the teachers said," rather than " $a$ teacher said."

\section{Findings}

Findings from this study are framed around the teacher desire that students with disabilities self-regulate their own learning. However, when students were unable, teachers lacked strategies for moving them beyond basic monitoring, and they believed that the "self" part of self-regulation meant that teachers should help, but only so much. This tension was dealt with by the teachers initiating and maintaining communication in the hopes that students would take up the work. They did so by offering advice about school program policies, working to notify students of resources available. 


\section{Initiating and Maintaining Communication}

The online teachers recognized when their students were experiencing challenges in one of two ways. First, online teachers noticed through conversation with students that some were struggling with the curriculum. In discussing academic progress with students, online teachers gained an understanding of student progress. The online teachers found it difficult, however, to interact with students at times due to many factors, including non-response to attempted communication. Though non-response was not an issue that online teachers experienced with all their students, it was present. When online teachers did communicate with students, they had to make judgments of student performance by drawing from their knowledge of the student and the online learning environment.

The most promising student-online teacher communication scenarios were ones that occurred on a preset schedule that included communication with students and parents. This communication was required to take place monthly. According to teacher logs, however, they spoke with their students with disabilities much more often, sometimes weekly.

Spoke with mother at length and [student]. Mother thinks he's not working enough, and [student] wanted me to discuss with her the unit 6 issue of doing 1 at a time. Reminded them both that I grade quickly so that he could still do one assignment each day if that's what she wants him to do. We discussed where he is now and also the one revision that has to be done right away. (Contact log. Ms. Smith. 5/06/14. Monthly phone call)

The online learning platform provided multiple student performance data sources for teachers to analyze. The data points that online teachers monitored most frequently were task completion and performance using a standardized curriculum. Timely task completion was crucial to student success in the online learning environment because it ensured they did not fall so far behind as to be unable to make up the required work by the end of the class. Online teachers monitored students' task completion through a curriculum dashboard. On this dashboard, incomplete assignments are indicated by red font. One educator described looking for these incomplete assignments as part of her morning ritual; specifically, she woke up and went to the computer to see how many "reds," or incomplete assignments, showed up from students in her teaching load.

They need to be engaging the curriculum in order to retain it. So, that's been my big thing, and that's going to be my main focus. I want to make sure I have no reds, I want to make sure these kids are constantly working and I've been activating these students this week. (Ms. Bongiovi, Interview 6, Line 221)

From there, Ms. Bongiovi discussed her push to have students consider completing their assignments as a game. She strategized which method of communication best connected with particular students and how long it had been since her last communication attempt with them and their parents. The "reds" on her dashboard became her workflow. Her objective for the day was to reduce the number of incomplete assignments through the vigilant use of the limited number of strategies at her disposal. Specifically, these strategies included (1) contacting students to tell them to log in, complete, or re-do assigned work, (2) contacting parents to tell their child to log 
in, complete, or re-do assigned work, and (3) notifying the families that the students could be dropped from the class if they continued to fail to make progress.

The other teachers also had routines to help students return to work after a period of inactivity. The following interview excerpt comes from Ms. Cardio. In her interviews, she discussed how helping students self-regulate their learning could not be done without also paying attention to their emotional self-regulation.

So I had that discussion with him last Wednesday. I gave him a task for the evening and then followed up at 8pm. He was very, very upset with me, for asking him to have a time constraint to have his work in that day. But it was because he was so far behind. So I was trying to really get something out of him, so I could evaluate it and see where to go from there. (Interview with Ms. Cardio, Interview 2, Line 21).

This description is interesting because of the manner in which the teacher attempted to help: by providing only one task. The student did not want to complete the task on the day that the teacher specified. Since the student was so far behind, the teacher rescinded some of the student's control over pace that is normally afforded online. In asking the student more about the task, Ms. Cardio learned the real issue was the student's not expecting an online physical education class to have any associated subject matter. He was still adjusting to the idea that the class would be more than keeping track of physical activity. For Ms. Cardio to get the student to work, she had to identify the source of his anger, and then in resolving the matter, provide additional information about the course. She then re-engaged the student in self-regulation of learning.

\section{Advising Students about Program Policies}

When students failed to make progress in the courses, teachers often reminded them that being in an online course was optional, and if it was not a good fit, they might need to return to a traditional setting. Removing students from the course was allowed after several weeks of no observable progress.

The last couple of weeks I've actually thinned out a lot of my students that just weren't working. So, I've been focusing on telling the students up front, "if you're not going to work, if you haven't submitted an assignment, then you don't have points so you aren't going to pass the test and then the class” (Ms. Bongiovi, Interview 6, Line 142).

The strategy of reminding the students that they might be removed from the course provided little self-regulated learning benefit to students. Instilling a sense of urgency was also present in the communication logs that students used.

This is an URGENT reminder you have only submitted 3 assignments! Please be sure to complete all assignments 1.00-1.05B and have a $\mathrm{C}$ or better overall in the class by Monday to successfully complete your grace period and remain in the course! (Contact log. Ms. Cassidy to student. 5/14/14. Attempted phone call, left message).

These strategies were intended to increase motivation for students to complete work, or they would not remain enrolled in the course. The strategies were particularly relevant for many of the 
students with whom these teachers were currently working; namely, high school seniors. Failure to pass online classes, especially core requirements such as math, English, and physical education meant failure to graduate in the current academic year. The online teachers were aware of the seriousness of failure to graduate. Their concern resulted in increased monitoring of student academic task completion instead of equipping students with strategies that lead to long term self-regulated learning.

Careful monitoring of student progress was considered essential to passing courses. Monitoring served as an overarching strategy that students with disabilities received, regardless of academic status in the class. This could have been an opportunity to engage in forethought and/or reflection processes. Instead, these moments often turned into discussions about how to keep the technology up and running. Specifically, students experienced issues with the computer timing out during important assignments or exams. Teachers then had to take up roles as advocates for their students in an effort to improve access to the online learning environment. In the following example, a teacher discussed the process of accommodating a student taking an exam. The focus in this example is on preparation for performance that accommodates physiology and what it takes to help the child perform alongside technology, with little time to spare for forethought and reflection grounded in cognitive skill.

I told you I have a student who needs to take breaks really frequently like every 10 to 15 minutes for a final exam. So, I'm working with the tech support to see how we can do this so that the software does not time out because that exam is coming up in about two weeks. And that's basically an accommodation for this child who had some very severe ADHD issues. He stands while he does the work, walks around dances around in between. But our software would time out within about three minutes or four minutes of being totally idle. Which also worries me when we have big essays or a large paragraph in reading on the final exam. (Ms. Smith, Interview 4, Line 56)

The teacher, through active knowledge of student behaviors, searched out answers to questions that would benefit the student during online examinations. If she had not communicated with the student upfront, she might have thought that the student was a non-worker. Advocacy comes as the teacher requests that the online learning platform be modified to accommodate the student performing in the online learning environment. Ultimately, this regulation, although not directly cognitive, is heavily teacher-controlled, rather than student regulated.

Teacher-controlled regulation of students, when they stayed in communication with the teacher, did not merely happen in terms of arranging for extra time or additional attempts to log into testing systems. It also came as teachers made efforts to prepare students in advance for the testing experience and encounter a low-stakes performance in preparation for an actual high stakes one. In the example below, Ms. Cardio addressed the issue of timed exams as an accommodation for students with disabilities.

I take that time to coach them for the exam because I don't feel that the assignments and projects really prepare the students for the final exam because you go from all these projects to a multiple choice and essay final exam. It's just [that] there's just no 
opportunity throughout to have like little 10, 20-point multiple choice quizzes for them to see what it's going to be like. (Ms. Cardio, Interview 4, Line 56)

Ms. Cardio showed a deep understanding of students with disabilities' performance and needs. Because she was concerned about the translation of short assignments into larger, longer tests, Ms. Cardio prepared students with disabilities to take exams by discussing their structure as well as her expectations for them to pass. She assessed this need by noting the lack of exam models her students had access to leading up to crucial tests and her awareness that students with disabilities needed these models to be successful. However, with her student load of more than 50 students with disabilities, walking each student through examples and preparing them for the test took much of her workday, along with holding small group lessons, grading assignments, and making contact with families.

\section{Using Planning Resources}

In addition, the teachers used strategies that aimed to offer pacing support for the academic performance of students with disabilities. Ultimately, the online teachers wanted their students to complete academic tasks according to a pacing guide that detailed when tasks were to be completed. One strategy used by teachers, once they became aware of non-working students, was to refer the student back to the pacing guide.

I tell them, "never let seven days go by without working.” As long as they're working every week and submitting assignments, that's really our only requirement. We like them to stay on pace, we have pace charts there for them to use-traditional paces, accelerated paces, whatever works for them, they can even create their own. (Ms. Cassidy, Interview 2, Line 225)

The pacing guide was intended to promote self-regulated learning for students in online learning environments, but some students were non-responsive to them. In some cases, teachers would tailor a pacing guide to meet the needs of a learner that had fallen behind. This new pacing guide provided information on how the student could complete missed work and get back on pace with upcoming academic tasks. The issuance of a new pacing guide was predicated on teacher communication with students and parents. The pacing guide served to mediate communication between students, parents, and teachers when the issue of non-work was present.

In addition to the pacing guide, teachers in this study referred students to resources that were embedded in the online learning curriculum. These resources included videos and graphic organizers that had been adapted to be accessible in any digital format and posted for all students in the school. According to school policy, the students were supposed to use these strategies when they experienced challenges with academic tasks.

[We use an] English I Student Help website and we're constantly adding to it and making it better, but for each lesson, all they have to do is go to that help website, click on the unit they're in, scroll down to their lesson, and it has the assignment right there for them. So they just click on the assignment, we've redone all of the graphic organizers and assignments for them so that they're in a format everyone can open-you can just write 
in the boxes, fill them in. So we've made it so easy for them, if they will just use it. (Ms. Cardio, Interview 6, Line 370)

Since these supports are available through the help website, students have to come to the conclusion themselves that they need help in order to use them, rather than considering the supports to be part of their normal work. In addition, these sources are made to be generally adaptable to a variety of courses at multiple grade levels. This is where multiple levels of selfregulation of learning come into play for teachers. They have to help students realize when they need support, identify what kind of support, select it from available resources, and then use the support. The teachers previously thought that once those resources were online, the students would move smoothly through the process. They were not expecting the students to need their assistance in finding them or directing them to the most helpful ones for a given task.

Students could use these resources as strategies to complete tasks but rarely did so. Frustration from the underuse of resources built into the online learning platform was often reported by the teachers.

I tell them all the time, "Have you been to the student help website? Everything you need is there." We have videos on everything you can imagine-grammar, punctuation, spelling, specific content areas for each unit. So they can click on a video and watch it and get help that way, which is really helpful for my special education students. We have, you know, just all sorts of resources that help them. (Ms. Cassidy, Interview 2, Line 187)

The teachers indicated that curriculum specialists had spent a great deal of time creating and maintaining these digital resources for this online learning environment as part of a school-wide interest in supporting students. Further, the teachers had to attend professional development activities regarding these resources and to learn about the curriculum that had also been created by course designers without teaching responsibilities. Under these circumstances, the teachers were directing students to school resources because they were more closely linked to the standardized curriculum. In Ms. Cassidy's case, she felt that if students accessed these resources, their performance and completion rates would improve. However, communicating with the student, supporting the student emotionally, advising them of policies, identifying the learning challenges, and providing direct support was not a smooth process. Further, although the teachers used these supports and strategies for students with disabilities more often, none of these were designed specifically for them. In other words, the major element of support for these students were teachers who were aware of their disability status and who were willing to increase the number of times they reminded them to work and repeat instructions on accessing schoolsponsored support.

\section{Discussion}

The findings of this study illustrate how several teachers in a particular context managed the challenges of supporting students with disabilities in completing online coursework. In this case, that context was a fully online state-sponsored virtual high school. The teachers were working with students who were mostly part-time, many of whom were working to earn credit for graduation, both initial credit and, in some cases, credit recovery. These teachers were 
certified in their subject areas, as well as special education, and assigned to share student loads. Although there is no expectation of generalizable findings, the conditions' credibility in qualitative research-prolonged engagement, persistent observation, peer debriefing, member checking, audit trails, and descriptive details - have been provided for readers of this study to decide which elements of the findings resonate their own circumstances (Lincoln \& Guba, 1985; Marshall \& Rossman, 2014).

Although this study consisted of a small number of teachers in one high-enrollment school, the findings are useful for understanding how self-regulation of learning potentially translates into high attrition in online education environments, especially for students with disabilities. When students stop working, teachers increase communication with them and their parents, remind them about various policies, provide advocacy, and direct them to resources for pacing and monitoring their performance. However, these monitoring strategies are unlikely to support self-regulated learning across a course because they do not introduce students to concepts of forethought as planning, strategies for performance, or self-assessment through reflection. The goal is always to move through the course in a timely manner, rather than take each task separately, decide what needs to be done and how do it, do the task, and think about whether the product is pleasing to the learner and efficacious as evidence for the demands of the course. The rest of this section focuses on developing potential sites for supporting selfregulation of learning, addressing the emotional demands of online learning for students with disabilities, and moving toward meaningful co-regulation.

\section{Developing Potential Sites for Supporting Self-Regulation of Learning}

In looking at these data, we saw little evidence that teachers were able to access resources that would support them in helping students engage in self-regulation of teaching. The pacing guide is potentially a site to develop forethought or even reflection, but currently it is used to tell students what lesson they should be working on to finish the course. Extending the guide into a task- or strategy planning mechanism instead of a mere time-keeping device and revisiting the pacing guide during weekly phone calls for more careful reflection could provide some foundation for students to construct, monitor, and adapt their learning (Pintrich, 2004). As we saw with Ms. Bongiovi, who discussed her dashboard lighting up red when her students were not working, teachers were being alerted to non-working students in ways that sent the message to them that they were task-managers, rather than instructors. This is also evident in the way in which the curriculum was provided to teachers with little room for modification. Since these teachers did not participate in curriculum making and they had little power to change the lesson content, all they could do was prompt students to log on and attempt to work through lessons. The "reds" on the dashboard regulate Ms. Bongiovi's behavior and give her information for reflection, but what is being regulated is her behavior in the form of attention to compliance instead of her time spent instructing students about subject matter.

In addition, the school provided resources on its main webpage for moving through the courses. The teachers directed their students to these resources, but these resources seemed to function more often as a last resort when frustration had already set in. Embedding these resources within lessons and tailoring resources to particular content might help students adapt their learning for improved performance. In addition, it might help for course designers to draw 
more attention to web-based resources early on in an assignment and teachers may design small group lessons where they model the construction of learning and demonstrate control over a task.

\section{Addressing the Emotional Demands of Online Learning}

These teachers knew that before enrolling in online work, one has to know the stakesthe risks and rewards of doing work online-in order to be successful. Unfortunately, these teachers lost more time that might have been spent in supporting self-regulation of learning when they provided emotional support to students who suddenly realized completing online courses would be difficult. Every course had heavy content demands and required planning, performance, and reflection for success. In this school, teachers described students with disabilities as becoming emotionally upset when they learned that the courses would require real work. There were no resources for dealing with this disruption. Therefore, teachers took up that responsibility and in so doing, more instructional time was swallowed up, making both teachers and students feel less control over the learning and responsible for the outcomes.

All four teachers attempted to tell students the intellectual and time demands of online learning. They reiterated these demands as situations arose that threatened students' ability to engage independently with the tasks. Ultimately, their work in helping students understand how to operate in the fully virtual environment in a practical sense (e.g., taking breaks) resulted in mostly teacher-controlled efforts, rather than truly self-regulated ones. This is different than in the review of literature where teachers present strategies to students and then students practice the strategies with the hope that it will become a routine (Graham \& Harris, 1993; Harris, Graham, \& Moore, 2006). What is happening in this context is that the teacher is keeping track of all the tasks and the need to produce a product is more important than the need to demonstrate a process and emotional stress is the result.

\section{Moving toward Meaningful Co-Regulation}

Part of the fully online learning context is that students perform their work asynchronously, away from the direct presence of a teacher. In such an environment, an agreement may emerge where students are expected to demonstrate learning by completing assignments, and teachers are expected to grade assignments and answer questions with all deliberate speed, instantaneously if possible. As long as both parties conform to expectation, little other communication seems necessary. After all, some of the students likely enrolled in fully online courses because they wanted to work independently and they are already able to exert control over learning tasks. However, when students without these skills fail online courses because they cannot assume control over their work, there is little chance that they will gain the self-efficacy integral to learning (Schunk \& Zimmerman, 2007).

Further, transitioning from brick-and-mortar environments undoubtedly shapes how expectations for teaching and learning are met for both teachers and students, as they move from daily unselfconscious interactions to highly structured ones that might occur only weekly or in the event of a problem. There were few opportunities to engage in reflective processes and fewer chances to record those and learn from them. When we asked the teachers what they realized while participating in this study, they all gave statements along these lines: "I learned that I do a lot for my special education students, I realized how important they are to me, and I wish I had more time to think about how my efforts help them.” Even so, teachers in this school had limited 
access to meaningful artifacts of progress and they might have benefitted from preparation to use a wider variety of the data being collected in their schools so that they would not have to enroll in a research study to learn how much they serve their students with disabilities.

While this study was focused on what teachers do to help students self-regulate their learning, the data also clearly illustrated the ways in which the teachers engaged in selfregulatory learning processes as they taught. Ms. Bongiovi offered the example of how the computer gave her the feedback she needed to define her teacher work-at least in part-as getting rid of reds, Ms. Smith’s careful orchestration of break times for her student during tests, Ms. Cassidy's frustration when students did not desire to use the help website materials without constant reminders, and Ms. Cardio's compassion for a student who learned that physical education online would require assignments designed to build content knowledge about the body all demonstrate the ways in which teachers are not just regulating students, but are co-regulating with them. The question is whether and how this co-regulation can be reframed to include the process of learning content as a focus.

\section{Conclusion}

If students are expected to be adept self-regulated learners, teachers need to understand the differences between teacher monitoring, strategy instruction, planning prompts, and reminders to self-reflect on performance (Zimmerman, 1998). Further, the reflection elements need to be more carefully embedded into the coursework at this school, and teachers and students may benefit from the chance to talk about what students learned, how they felt about learning it, and what they plan to apply from tasks learned to another. At the school level, the findings of this study point to a need for course designers to attend more fully to what they can put at students' fingertips in terms of self-regulation support, rather than compiling it in the places students will not see without prompting from teachers and teachers need a greater sense of their role in directing curriculum tasks, as opposed to merely monitoring them.

Researchers could help virtual schools, in their various configurations, determine how to embed all phases self-regulation of learning into online coursework. Additional projects might be conducted around what teachers can do to help students with disabilities, specifically in terms of self-regulation, and what teachers might be able to profitably do for all. Finally, support for selfregulation and the way in which IEPs are implemented would benefit from stronger overlap. Although these students were only part-time, and they had a traditional school to manage their disability service delivery, there was no evidence of collaboration between the online program and the traditional school. As such, the service delivery was left to teachers, which meant significant extra work for them in terms of contacting the students and continuing to send them to resource sites that they did not deign to use.

In terms of policy-making, students with disabilities enrolled in online courses need teachers who understand their needs and are mobilized and empowered to meet them. Designing policies that enable teachers to engage more fully in self-regulation of learning would be the first step in determining the degree to which such practices would help. Finally, policy steps must be taken that more fully attend to the ways in which service delivery is handled and monitored, rather than leaving the work to teachers to make extra phone calls and comfort the students. 


\section{References}

Basham, J.D., Stahl, S., Ortiz, K., Rice, M.F., \& Smith, S. (2015). Equity matters: Digital \& online learning for students with disabilities. Lawrence, KS: Center on Online Learning and Students with Disabilities.

Barbour, M. K., \& Mulcahy, D. (2004). The role of mediating teachers in Newfoundland's new model of distance education.

Butler, D. L., \& Winne, P.H. (1995). Feedback and self-regulated learning: A theoretical synthesis. Review of Educational Research, 65(3), 245-281.

Bernier, A., Carlson, S. M., \& Whipple, N. (2010). From external regulation to self-regulation: Early parenting precursors of young children's executive functioning. Child Development, 81(1), 326-339.

Boekaerts, M., \& Corno, L. (2005) Self-regulation in the classroom: A perspective on assessment and intervention. Applied Psychology: An International Review, 54(2), 199-231.

Cavanaugh, C. (2007). Student achievement in elementary and high school. Handbook of distance education, 2, 157-168.

Clandinin, D. J., Murphy, M. S., Huber, J., \& Orr, A. M. (2009). Negotiating narrative inquiries: Living in a tension-filled midst. The Journal of Educational Research, 103(2), 81-90.

de la Varre, C., Irvin, M. J., Jordan, A. W., Hannum, W. H., \& Farmer, T. W. (2014). Reasons for student dropout in an online course in a rural K-12 setting. Distance Education, 35(3), 324-344.

Deshler, D., Rice, M., \& Greer, D. (2014). Which demographic variables predict final grades for high school students enrolled in online English/ELA courses? Results from a regression analysis. Presentation at the annual meeting of the American Educational Research Association. Philadelphia, PA.

Deshler, D., Smith, S., Greer, D., \& Rice, M. (2014, April). The barriers, challenges, and opportunities of online learning environments for SWDs. Presentation at the annual meeting of the Council of Exceptional Children. Philadelphia, PA.

Fernandez, H., Ferdig, R. E., Thompson, L. A., Schottke, K., \& Black, E. W. (2016). Students with Special Health Care Needs in K-12 Virtual Schools. Journal of Educational Technology \& Society, 19(1), 67-75.

Freidhoff, J. R. (2015). Michigan’s K-12 virtual learning effectiveness report 2013-14. Lansing, MI: Michigan Virtual University. Retrieved from http://media.mivu.org/institute/pdf/er_2014.pdf 
Fritschmann, N. S., Deshler, D. D., \& Schumaker, J. B. (2007). The effects of instruction in an inference strategy on the reading comprehension skills of adolescents with disabilities. Learning Disability Quarterly, 30(4), 245-262.

Gemin, B., Pape, L., Vashaw, L., \& Watson, J. (2015). Keeping pace with K-12 digital learning: An annual review of policy and practice.

Graham, S., \& Harris, K. R. (1993). Self-regulated strategy development: Helping students with learning problems develop as writers. The Elementary School Journal, 169-181.

Harris, K. R., Graham, S., \& Mason, L. H. (2006). Improving the writing, knowledge, and motivation of struggling young writers: Effects of self-regulated strategy development with and without peer support. American Educational Research Journal, 43(2), 295-340.

Lincoln, Y. S., \& Guba, E. G. (1985). Naturalistic inquiry. Thousand Oaks, CA: Sage publications.

Marshall, C., \& Rossman, G. B. (2014). Designing qualitative research. Thousand Oaks, CA: Sage publications.

Mathison, S. (1988). Why triangulate? Educational Researcher, 17(2), 13-17.

Pintrich, P. R. (2004). A conceptual framework for assessing motivation and self-regulated learning in college students. Educational Psychology Review, 16(4), 385-407.

Sawyer, R. J., Graham, S., \& Harris, K. R. (1992). Direct teaching, strategy instruction, and strategy instruction with explicit self-regulation: Effects on the composition skills and self-efficacy of students with learning disabilities. Journal of Educational Psychology, 84(3), 340-352.

Schunk, D. H., \& Zimmerman, B. J. (2007). Influencing children's self-efficacy and selfregulation of reading and writing through modeling. Reading \& Writing Quarterly, 23(1), 7-25.

Schunk, D. H. (2005). Self-regulated learning: The educational legacy of Paul R. Pintrich. Educational Psychologist, 40(2), 85-94.

Watson, J., Pape, L., Murin, A., Gemin, B., \& Vashaw, L. (2014). Keeping pace with K-12 digital learning: An annual review of policy and practice. Evergreen Education Group.

Watson, J., \& Kalmon, S. (2005). Keeping pace with K-12 online learning: A review of statelevel policy and practice. Naperville, IL: Learning Point Associates. 
Wehmeyer, M. L., Smith, S. J., Palmer, S. B., \& Davies, D. K. (2004). Technology use by students with intellectual disabilities: An overview. Journal of Special Education Technology, 19(4), 7-21.

Weinstein, C. E., \& Mayer, R. E., (1986). The teaching of learning strategies. In Wittrock, M. C. (Ed.) Handbook of research on teaching, 3rd ed. (pp. 315-327). New York, NY: Macmillan.

Zimmerman, B. J. (2008). Investigating self-regulation and motivation: Historical background, methodological developments, and future prospects. American Educational Research Journal, 45(1), 166-183.

\section{Funding Statement}

The contents of this article were developed under a grant from the US Department of Education \#H327U110011. However, those contents do not necessarily represent the policy of the US Department of Education, and you should not assume endorsement by the Federal Government. Project Officer, Celia Rosenquist. 